\title{
Validity of Staining and Marginal Ditching as Criteria for Diagnosis of Secondary Caries Around Occlusal Amalgam Restorations: An In Vitro Study
}

\author{
Claudia Silami MAGALHÃES ${ }^{1}$ \\ Amanda Beatriz Dahdah Aniceto de FREITAS ${ }^{2}$ \\ Allyson Nogueira MOREIRA ${ }^{1}$ \\ Efigênia Ferreira FERREIRA ${ }^{3}$
}

\author{
${ }^{1}$ Department of Restorative Dentistry, Dental School, Federal University of Minas Gerais, Belo Horizonte, MG, Brazil \\ ${ }^{2}$ Dental School, Faculty of Administrative Studies of Minas Gerais, Belo Horizonte, MG, Brazil \\ ${ }^{3}$ Department of Community and Preventive Dentistry, Dental School, \\ Federal University of Minas Gerais, Belo Horizonte, MG, Brazil
}

\begin{abstract}
This study determined the validity of marginal ditching and staining as criteria for the diagnosis of secondary caries around amalgam restorations. One hundred and twenty-four Class I amalgam restorations on extracted human teeth were submitted to standardized clinical examinations. A calibrated examiner recorded the presence of ditching in the tooth/restoration interface, the occurrence of bluish-grey staining on the occlusal surface, and their relationship with the presence and severity of secondary carious lesions. Examinations were repeated after 4 days to calculate the intra-examiner reliability. Stereomicroscopic inspection of the serial tooth sections was used as the gold-standard. Six teeth were lost during the study. Of the 118 remaining teeth, 19 (16\%) showed occlusal bluish-grey staining and 26 showed more than $0.20 \mathrm{~mm}$ wide marginal ditches. Of the latter, 14 presented narrow ditches $(0.20-0.45 \mathrm{~mm})$, while 12 presented wide ditches $(0.45 \mathrm{~mm})$. The evaluation criteria presented low sensitivity and positive predictive values. Positive and negative likelihood ratios showed that the criteria exhibited, indistinctly, the same odds to determine a positive or negative result for a diseased or healthy tooth. It was concluded that marginal ditching and staining were not valid criteria for the diagnosis of secondary caries around occlusal amalgam restorations.
\end{abstract}

Key Words: marginal ditching, staining, dental amalgam, dental restoration, diagnosis, secondary caries.

\section{INTRODUCTION}

Amalgam restoration is still considered one of the main restorative treatment options in several dental practices, due to its low cost and long-term cost-effectiveness. The clinical diagnosis of secondary caries has been the most common indication for replacement of amalgam restorations (1).

Secondary caries are derived from the action of cariogenic biofilms at the restoration margins. Superficial carious lesions are more easily detected. However, the determination of lesion extension is hindered by the presence of restoration and can be observed only when an advanced stage is reached, causing enamel discolor- ation, cavitation, and even dental fracture.

The relationship between the width of the marginal defect and the presence of secondary carious lesions has been verified by clinical and laboratory studies. Marginal ditches wider than $50 \mu \mathrm{m}$ at the tooth/amalgam interface correlate with the presence of recurrent caries (2). A marked increase in the prevalence of secondary carious lesions has been shown to be associated with a decrease in marginal integrity. Gingival margins of Class II and Class V are at higher risk of having secondary caries, which is proportional to the degree of marginal damage, whereas no such relationship exists on occlusal surfaces (1). Some authors have stated that the presence of defective margins does not necessarily indicate need 
for restoration replacement, especially since they tend to be poor predictors of the occurrence of adjacent carious lesions (3). Microorganisms have been found at restoration margins with wide ditches in significantly higher quantities than those found in narrow ditches, but no significant relationship has been observed between grayish staining adjacent to the restoration and the number of bacteria (4). Pimenta et al. (5) found no statistically difference between the presence of secondary carious lesions in restorations with ditches as compared to those that appeared satisfactory. This finding confirms the difficulty to precisely diagnose secondary carious lesions based on the presence of naked-eye detectable ditches.

In a previous study (6), when bluish-grey staining was used as a criterion to indicate restoration replacement, only $50 \%$ of the occlusal secondary caries were correctly diagnosed. The presence of bluish-grey stains on the proximal walls adjacent to Class II amalgam restorations was ineffective in predicting secondary carious lesions. However, their absence was considered as a good predictor of healthy teeth.

Considering the controversial results found in the literature, whether or not the presence of ditches and bluish-grey discoloration at the margins of amalgam restorations may in fact be associated with secondary carious lesions is still inconclusive. Therefore, the purpose of this in vitro study was to determine the validity of marginal ditching and staining as criteria for the diagnosis of carious lesions adjacent to occlusal amalgam restorations. It was hypothesized that marginal ditching and staining are valid criteria to diagnosis of secondary caries in amalgam restorations.

\section{MATERIAL AND METHODS}

This study was approved by the Research Ethics Committee of the Federal University of Minas Gerais, Brazil (protocol \#194/02). The sample consisted of 124 extracted human teeth ( 40 premolars and 84 molars) with class I amalgam restorations and no visible cavitation at the tooth/restoration interface. The teeth were stored in $2 \%$ formalin neutral solution for $48 \mathrm{~h}$ for disinfection and fixation, and then cleaned and embedded in colorless chemically activated acrylic resin (Jet; Artigos Odontológicos Clássico Ltda., São Paulo, SP, Brazil). Blocks with 3 teeth each were obtained to facilitate handling and to standardize positioning during the subsequent stages.

To simulate clinical examinations under con- trolled conditions, one tooth at a time from each block was analyzed, under the same operating light. Then, the block was stored in filtered water since prolonged exposure to air could cause dehydration and contribute to the appearance of demineralized areas. The teeth were air dried for 5 to $7 \mathrm{~s}$ and then subjected to naked-eye inspection, that is, using neither a clinical mirror nor any magnifying instrument. The entire tooth/restoration interface was used as a sample unit.

Bluish-grey staining, small and large ditches at the restoration margins were recorded for evaluation. Probing was restricted to cases where the presence of marginal ditches placed the tissue integrity in question. In such situations, light probing was performed to verify tissue consistency.

The marginal ditches were classified as either small $(0.2-045 \mathrm{~mm}$ thick) or large $(>0.45 \mathrm{~mm})$. This difference was assessed by carefully inserting the active point of a dental explorer $($ diameter $=0.2 \mathrm{~mm})($ Golgran Ind. e Com. de Instrumental Odontológico Ltda., São Paulo, SP, Brazil) and/or a periodontal probe (diameter $=0.45 \mathrm{~mm}$ ) (Prudent Dental Trinks Ind. e Com., São Paulo, SP, Brazil) into the gap of the tooth/restoration interface. All teeth were reexamined after 4 days under the same conditions in order to determine the intraexaminer reproducibility.

The teeth were individually embedded in polyester resin (Resina Cristal 112-E; Casa da Resina, Belo Horizonte, MG, Brazil), and longitudinally cut in a buccolingual direction using a $400-\mu \mathrm{m}$ diamond saw under constant water cooling (Isomet II-1180; Low Speed Saw, Buehler Ltd., CA, USA). Each molar and premolar produced approximately nine and five $700-\mu \mathrm{m}-$ thick-sections, respectively. Both sides of each section were evaluated with a stereomicroscope (Zeiss model Stemi DV4, Gottingen, Germany) at $\times 32$ magnification, and the most severely affected section determined the lesion depth.

The validation criteria were ranked according to the severity of the secondary carious lesions $(7,8)$. For descriptive purposes, the difference between secondary carious lesions and residual carious lesions was proposed. However, when the data were analyzed, such lesions were grouped as "demineralizations".

The results were assessed according to 3 cutoff points to indicate "healthy" and "diseased" teeth: 1 . Considering all enamel and dentin demineralizations as "disease"; 2. Considering only dentin demineralizations 
as "disease", regardless of the degree of tissue disorder and 3. Considering only dentin demineralizations characterized as irreversible - advanced tissue destruction as "disease".

Cohen's kappa statistic was used to assess intrarater reliability of the observer with regard to the diagnosis criteria. Sensitivity, specificity, positive and negative predictive values (PPV, NPV), accuracy, positive and negative likelihood ratios (LR+, LR-), and the Youden index were calculated for the bluish-grey discoloring and the presence of ditches in relation to the presence of secondary carious lesions in enamel and dentin.

\section{RESULTS}

Cohen's kappa statistics indicated good agreement of the observer with regard to the diagnosis criteria (0.68). Of the 124 teeth of the sample, six (4.84\%) were lost or discarded because they were fractured during sectioning (4) or due to proximal lesions adjacent to restorations as seen during steromicroscopic examination (2). The final sample consisted of 118 permanent teeth (39 premolars and 79 molars).

The stereomicroscopic analysis showed 45 teeth (40 molars - 50.63\%, and 5 premolars - $12.82 \%$ ) with secondary caries. Thirty-one lesions were in enamel and 14 involved dentin, 8 of which being irreversible demineralizations in the outer half. Irreversible demineralization in the inner half of dentin was not associated with secondary lesions (Table 1). Sixty-seven teeth showed residual carious lesions (27 in enamel and 40 in dentin). Irreversible demineralization was found in 11 teeth, either superficially $(n=8)$ or deeply $(n=3)$.

Fifteen teeth showed secondary lesions in enamel and residual lesions in dentin simultaneously, while 1 tooth exhibited a secondary lesion in superficial dentin and a residual lesion in deep dentin. These specimens, including 96 teeth, were counted only once when the designation of "demineralizations" was created.

Liners and bases were found in 27 teeth and cavity varnishes in 28 . Association of bases and varnishes were found in eight teeth.

Nineteen of the 118 teeth (16\%) showed bluishgrey occlusal staining. Table 2 shows the relationship between occlusal bluish-grey staining and dentinal demineralization concerning cutoff points 2 and 3 .

Table 3 relates marginal ditches to secondary carious lesions. Twenty-six teeth of the sample showed marginal ditching wider than $0.20 \mathrm{~mm}$. Fourteen teeth presented narrow ditches $(0.20-0.45$ wide), of which 11 were healthy and 3 had secondary carious lesions (1 in enamel and 2 extending into dentin). Twelve teeth presented wide ditches (wider than $0.45 \mathrm{~mm}$ ); 3 of them were healthy and 9 had secondary carious lesions (4 in enamel and 5 in dentin).

Sensitivity, specificity, positive and negative predictive values, accuracy, positive and negative likelihood ratios, as well as the Youden index, calculated for the occlusal bluish-grey discoloration and presence of fissures and ditches in relation to the presence of secondary carious lesions in enamel and dentin, are shown in Tables 4 and 5, respectively.

Table 1. Sample characterization concerning the origin and severity of demineralization found during validation examination.

\begin{tabular}{|c|c|c|c|c|c|c|}
\hline \multirow[t]{2}{*}{ Origin of lesions } & \multicolumn{2}{|c|}{ Depth of demineralization } & \multirow{2}{*}{ Total } & \multicolumn{2}{|c|}{$\begin{array}{c}\text { Severity of dentinal } \\
\text { demineralization }\end{array}$} & \multirow{2}{*}{ Total } \\
\hline & Enamel* & Dentin & & Reversible & Irreversible & \\
\hline Secondary lesion & 31 & 14 & 45 & 6 & 8 & 14 \\
\hline Residual lesion & 27 & 40 & 67 & 29 & 11 & 40 \\
\hline Total & 58 & 54 & 112 & 35 & 19 & 54 \\
\hline $\begin{array}{l}\text { Secondary and residual } \\
\text { lesions } * *\end{array}$ & 15 & 1 & 16 & 1 & - & - \\
\hline Total demineralization & 43 & 53 & 96 & 34 & 19 & 53 \\
\hline
\end{tabular}

*The demineralizations that reached and involved the dentinoenamel junction were considered as enamel lesions. ** When secondary and residual lesions occurred in the same teeth, the more superficial lesions were excluded. 


\section{DISCUSSION}

The data from clinical studies showed that 50 percent of restorations in adults are replaced because of the diagnosis of recurrent caries (1). The prevalence of secondary caries observed in this study varied from 16 to $81 \%$, depending on the cutoff point, which brings the criteria dentists are using for diagnosis and treatment into question.

Stereomicroscopic examination is often used as the gold-standard for the validation of diagnostic instruments for primary carious lesions (9-11), but there is still a lack of reports regarding its use in methods for the detection of lesions adjacent to restorations $(12,13)$. In the present study, it was difficult to determine the presence and extension of carious lesions under stereomicroscopy. In spite of being frequently used as the gold-standard, some aspects of this method are not clearly described in the literature.

Some in vitro studies have used hemisectioning of the specimens followed by stereomicroscopic examination as the gold-standard $(9,10)$. In the present study, the teeth were cut into various sections because sectioning the teeth in only 2 halves may not be sufficient to reveal carious lesions in the outer regions of occlusal ditches, which can result in an underestimation of the real prevalence of carious lesions in the sample (8).

In this study, the distinction between secondary and residual carious lesions was also difficult as the teeth were evaluated in only one instance of the validation method, which did not take into account the dynamics of the caries process. Secondary carious lesions were, by definition, those which were closely connected to the lateral walls of a restoration, either confined to enamel or

Table 2. Relationship between occlusal bluish-grey staining and the gold-standard at the dentinal cutoff points.

\begin{tabular}{|c|c|c|c|c|}
\hline \multirow[t]{3}{*}{$\begin{array}{l}\text { Occlusal bluish- } \\
\text { grey staining }\end{array}$} & \multicolumn{4}{|c|}{$\begin{array}{l}\text { Stereomicroscopic examination } \\
\text { (gold standard) }\end{array}$} \\
\hline & \multicolumn{2}{|c|}{ Cutoff point 2} & \multicolumn{2}{|c|}{ Cutoff point 3} \\
\hline & Caries & Healthy & Caries & Healthy \\
\hline Present & $13 \mathrm{TP}$ & $06 \mathrm{FP}$ & $03 \mathrm{TP}$ & $16 \mathrm{FP}$ \\
\hline Absent & $40 \mathrm{FN}$ & $59 \mathrm{TN}$ & $16 \mathrm{FN}$ & $83 \mathrm{TN}$ \\
\hline
\end{tabular}

extended into dentin. Residual carious lesions included those that were strictly located on the cavity floor and those located in dentin that not connected to enamel secondary lesions in any of the sections (1).

It is important to point out that the differentiation between secondary carious lesions and residual lesions was established only to characterize the sample as no diagnostic test has yet been able to precisely determine the origin of the lesions. The clinical manifestations of such lesions were evaluated on the whole as demineralizations so as to compose decision matrices and, subsequently, assess the performance of the diagnostic methods.

The literature is quite inconclusive regarding the criterion that should be used to determine the extension of carious lesions. While some authors have used dentin staining as a criterion to define the maximum extension of the carious process, others have emphasized that there must be a disorganization of the dental structure for the tissue to be considered as affected $(7,8,10,13)$. Therefore, the limited comparability among several validation studies is clear as the definition of a gold standard method varies among them (14).

The present study attempts to solve this dilemma by establishing different cutoff points for dentinal lesions: cutoff point 2 - considering all the cases with dentinal staining (brown, grey, orange, and/ or black) as positive; and cutoff point 3 - considering only the cases with evident irreversible disorganization of the dentinal structure as positive. The importance of differentiating such conditions lies in the fact that dentinal carious lesions exhibit 2 chemically and structurally different areas. The external area is irreversibly denatured, infected, nonremineralizable and should be removed during restorative treatment. The internal area, however,

Table 3. Relationship between the ditches wider than $0.20 \mathrm{~mm}$ and the gold-standard.

\begin{tabular}{lccc}
\hline \multirow{2}{*}{$\begin{array}{l}\text { Marginal } \\
\text { ditching }\end{array}$} & \multicolumn{3}{c}{ Presence of secondary carious lesions } \\
\cline { 2 - 4 } & Diseased* & Healthy & Total \\
\hline Present & $12 \mathrm{TP}$ & $14 \mathrm{FP}$ & 26 \\
Absent & $33 \mathrm{FN}$ & $59 \mathrm{TN}$ & 92 \\
Total & 45 & 73 & 118 \\
\hline
\end{tabular}

*All demineralizations (in enamel or dentin) were considered as "disease" (cutoff point 1). TP = true-positive; FP= false-positive; $\mathrm{TN}=$ true-negative; $\mathrm{FN}=$ false-negative. 
is reversibly denatured, non-infected, remineralizable, and should be preserved.

Based on the concept of disease reversibility, many authors have established the cutoff point at the amelodentinal junction $(11,15)$ and traditionally consider that the restorative treatment is necessary as soon as the lesion reaches the dentin. Other authors (13), however, take the pure concept of the disease and, in such conditions, classify enamel-restricted caries as disease. An important cutoff point for the clinician would be demineralized and infected dentin, which represents the stage when operative intervention is required (9). Considering the lack of agreement regarding which cutoff point should be used, the present study opted for 3 cutoff points: cutoff point 1, where enamel or dentin demineralizations were considered a "disease"; cutoff point 2 , where only teeth with dentinal demineralization are considered "diseased"; and cutoff point 3, where "disease" meant only dentin demineralizations with irreversible dentinal disorganization.

In this study, the sensitivity value of the bluishgrey-staining criterion was low ( $\mathrm{s}=0.25$ at cutoff point 2 ), corresponding to half the value obtained by Rudolphy et al. (6), even though both studies were methodologically similar. The specificity values were equivalent and high ( $\mathrm{s}=0.91$ at cutoff point 2 ). However, in contrast to the latter study, where the moderate sensitivity value was compensated by high PPV and NPV, rendering it useful

Table 4. Validity indicators for the criterion "occlusal-bluishgrey-staining" for the diagnosis of secondary carious lesions at two dentin cutoff points.

\begin{tabular}{lcc}
\hline Indicator & Cutoff point 2 & Cutoff point 3 \\
\hline Sensitivity & 0.25 & 0.16 \\
Specificity & 0.91 & 0.84 \\
Accuracy & 0.61 & 0.73 \\
PPV & 0.68 & 0.16 \\
NPV & 0.60 & 0.84 \\
LR+ & 2.66 & 0.98 \\
LR- & 0.83 & 1.00 \\
Youden index & 0.16 & $\mathrm{Z}$ \\
\hline
\end{tabular}

Cutoff point 2 = only dentinal demineralization is considered disease; Cutoff point $3=$ only irreversible dentinal demineralization is considered disease; $\mathrm{PPV}=$ positive predictive value; $\mathrm{NPV}=$ negative predictive value; $\mathrm{LR}+=$ positive likelihood ratio; $\mathrm{LR}-=$ negative likelihood ratio. as a diagnostic aid, in the present study, due to the imbalance between sensitivity and specificity with lower PPV (0.68) and NPV (0.60), it could be concluded that the occlusal-staining criterion presented a low value in the diagnosis of dentin demineralizations. Kidd et al. (16), found a statistically significant relationship between tissue softening at the amelodentinal junction and the degree of dentinal staining adjacent to aesthetic and amalgam restorations. For this criterion, the estimated values of sensitivity and specificity were 0.68 .

While the present study included teeth with or without occlusal staining and marginal ditches, other researchers used only teeth with at least one of these aspects (6), which may in fact explain such a value discrepancy. In yet another study, the teeth were included in the sample contemplating various types of doubtful conditions and levels of dental exposure (16).

With regard to irreversible dentinal lesions, the bluish-grey-staining criterion was unable to predict them adequately. At the cutoff point 3, the sensitivity and PPV were extremely low (0.16), while LR+ and LR- were approximately 1 , thereby showing that the criterion implied the same odds for determining a positive or negative result for a diseased or healthy tooth, indistinctly. The Youden index, equal to zero, confirmed that the criterion is expressively specific $(\mathrm{s}=0.84)$.

The bluish-grey staining was not an adequate criterion for the prediction of dentin demineralizations. However, the high NPV at cutoff point 3 suggests that the lack of stains predicts either a healthy condition or

Table 5. Validity indicators of the criterion "presence of marginal ditching" for the diagnosis of secondary carious lesions.

\begin{tabular}{lc}
\hline Indicator & Corresponding values \\
\hline Sensitivity & 0.27 \\
Specificity & 0.81 \\
Accuracy & 0.60 \\
PPV & 0.46 \\
NPV & 0.64 \\
LR+ & 1.39 \\
LR- & 0.90 \\
Youden index & 0.08 \\
\hline
\end{tabular}

$\mathrm{PPV}=$ positive predictive value $\mathrm{NPV}=$ negative predictive value; $\mathrm{LR}+=$ positive likelihood ratio; $\mathrm{RV}-=$ negative likelihood ratio. 
a reversible demineralization in dentin. Similar results are reported in the literature. Observing the relationship between bluish-grey staining and dentinal demineralization, even when using different indicators, it could be concluded that the color adjacent to a restoration was a poor criterion to predict a subjacent dentinal exposure $(4,17)$. On the other hand, the absence of staining represents a good indicator of the absence of disease (18).

For the ditching criterion, the sensitivity $(\mathrm{s}=0.27)$ and the PPV (0.46) were low; whereas the NPV was only moderate $(0.64)$. However, the specificity was high $(\mathrm{s}=0.81)$. The low Youden index value $(0.08)$ indicates that this is not an adequate criterion to diagnose secondary caries, especially since it favors specificity rather than sensitivity. The low $\mathrm{LR}+(1.39)$ and the high LR- (0.90) revealed that such a criterion is incapable of correctly distinguishing healthy from decayed teeth. These results agree with those of other studies which concluded that marginal ditching was a poor predictor of secondary carious lesions $(3,5,6,16)$.

Divergent results were also found in the literature. Marginal defects wider than $50 \mu \mathrm{m}$ have been considered as a predisposing factor for the development of secondary carious lesions in occlusal amalgam fillings (2). However, this result should be interpreted cautiously as a sample of high-caries-risk adolescents was used in that study, and the criteria for defining carious lesions may differ from that currently used.

Kidd et al. (4) did not find significant difference between the infection level of the dentin adjacent to intact amalgam restorations and those with narrow fissures, but samples with wide ditches showed a higher number of associated bacteria. In an in vivo study with a small sample size, Hodges et al. (17) found direct association between the width of the marginal fissure and the presence of secondary carious lesions extending into the dentin. However, the results obtained by this criterion in the present study should be evaluated with care since $26(22 \%)$ teeth exhibited visible ditches, while secondary carious lesions were detected in only 12 teeth $(10 \%)$. Careful analysis of the teeth revealed a tendency: the wider the ditch, the higher the association with secondary lesions. This hypothesis should be confirmed by further studies, using a larger number of teeth with occlusal restorations surrounded by marginal defects.

The presence of ditches and bluish-grey staining at the margins of occlusal amalgam restorations was not capable of predicting secondary carious lesions, and were considered as invalid criteria for the prediction of dentin demineralization.

\section{RESUMO}

Este estudo determinou a validade de fendas marginais e manchamentos oclusais como critérios para o diagnóstico de cárie adjacente a restaurações de amálgama. Cento e vinte e quatro dentes humanos extraídos, restaurados com amálgama Classe I, foram submetidos a exame clínico em condições padronizadas. Um examinador treinado registrou a presença de fendas na interface dente/restauração, a ocorrência de manchamento cinza-azulado na superfície oclusal e sua relação com a presença e severidade de lesões secundárias de cárie. Os exames foram repetidos após 4 dias para cálculo da confiabilidade intraexaminador. A inspeção de cortes seriados ao estereomicroscópio foi utilizada como padrão-ouro. Seis dentes foram perdidos durante o estudo. Dos 118 restantes, $19(16 \%)$ apresentaram manchamento oclusal cinza/ azulado e 26 apresentavam fendas marginais com largura superior a $0,20 \mathrm{~mm}$, sendo que destes 14 tinham fendas estreitas e 12 fendas amplas. Os critérios de avaliação apresentaram valores de sensibilidade e preditivo positivo extremamente baixos, enquanto a razão de verossimilhança positiva e a razão de verossimilhança negativa evidenciaram que os critérios apresentaram a mesma chance de determinar um resultado positivo ou negativo para um dente doente ou hígido, indistintamente. Pode ser concluído que fendas/valamentos e manchamentos oclusais não se mostraram como critérios válidos para determinar presença de cárie adjacente a restaurações de amálgama.

\section{ACKNOWLEDGEMENTS}

The authors would like to express their gratitude to Dr. Wagner Reis da Costa Campos of the Structural Integrity Service, Center of Nuclear Technology Development (CDTN), for the facilities.

\section{REFERENCES}

1. Mjör IA. Clinical diagnosis of recurrent caries. J Am Dent Assoc 2005;136;1426-1433.

2. Jorgensen KD, Wakumoto S. Occlusal amalgam fillings: marginal defects and secondary caries. Odont Tidsskr 1968;76:43-54.

3. Moncada G, Fernández E, Martín J, Arancibia C, Mjör IA, Gordan $\mathrm{VV}$. Increasing the longevity of restorations by minimal intervention: a two-year clinical trial. Oper Dent 2008;33:258-264.

4. Kidd EAM, Joyston-Bechal S, Beighton D. Marginal ditching and staining as a predictor of secondary caries around amalgam restorations: a clinical and microbiological study. J Dent Res 1995; $74: 1206-1211$.

5. Pimenta LAF, Navarro MFL, Consolaro A. Secondary caries around amalgam restorations. J Prosthet Dent 1995;74:219-222.

6. Rudolphy MP, Van Amerongen JP, Penning C, Ten Cate JM. Grey discolouration and marginal fracture for the diagnosis of secondary caries in molars with occlusal amalgam restorations: an in vitro study. Caries Res 1995;29:371-376.

7. Downer MC. Concurrent validity of an epidemiological diagnostic system for caries with the histological appearance of extracted 
teeth as validating criterion. Caries Res 1975;9:231-246.

8. Hintze H, Wenzel A. Diagnostic outcome of methods frequently used for caries validation. A comparison of clinical examination, radiography and histology following hemisectioning and serial tooth sectioning. Caries Res 2003;37:115-124.

9. Ekstrand KR, Ricketts DNJ, Kidd EAM. Reproducibility and accuracy of three methods for assessment of demineralization depth on the occlusal surface: an in vitro examination. Caries Res 1997;31:224-231.

10. Bamzahim M, Shi XQ, Angmar-Månsson B. Secondary caries detection by DIAGNOdent and radiography: a comparative in vitro study. Acta Odontol Scand 2004;62:61-64.

11. Wenzel A, Verdonschot EH, Truin GJ, König KG. Accuracy of visual inspection, fiber-optic transillumination, and various radiographic image modalities for the detection of occlusal caries in extracted non-cavitated teeth. J Dent Res 1992;71:1934-1937.

12. Espelid I, Tveit AB. Diagnosis of secondary caries and crevices adjacent to amalgam. Int Dent J 1991;41:359-364.

13. Nytun RB, Raadal M, Espelid I. Diagnosis of dentin involvement in occlusal caries based on visual and radiographic examination of the teeth. Scand J Dent Res 1992;100:144-148.
14. Ando M, Gonzalez-Cabezas C, Isaacs RL, Eckert GJ, Stookey GK Evaluation of several techniques for the detection of secondary caries adjacent to amalgam restorations. Caries Res 2004;38:350356.

15. Pereira AC, Eggertsson H, Martinez-Mier EA, Mialhe FL, Eckert GJ, Zero DT. Validity of caries detection on occlusal surfaces and treatment decisions based on results from multiple caries-detection methods. Eur J Oral Sci 2009;117:51-57.

16. Kidd EAM, Joyston-Bechal S, Beighton D. Diagnosis of secondary caries: a laboratory study. Br Dent J 1994;176:135-139.

17. Hodges DJ, Mangum FI, Ward MT. Relationship between gap width and recurrent dental caries beneath occlusal margins of amalgam restorations. Community Dent Oral Epidemiol 1995;23:200-204.

18. Rudolphy MP, Van Loveren C, Van Amerongen JP. Grey discolouration for the diagnosis of secondary caries in teeth with class II amalgam restorations: an in vitro study. Caries Res 1996;30:189193.

Accepted October 13, 2009 